\title{
Investigation of the Head's Dynamic Response to Boxing Punch Using Computer Simulation
}

\author{
Neda Boroushak', Hasan Khoshnoodi², Mostafa Rostami ${ }^{3}$ \\ Affiliations: 'Sport Science Research Institute, Tehran, Iran, ${ }^{2}$ sslamic Azad University, Shoushtar Branch, Department of Mechanical Engineering,
} Shoushtar, Iran, ${ }^{3}$ Amirkabir University, Biomedical Engineering Department, Tehran, Iran

Correspondence: N. Boroushak, Sport Science Research Institute, No. 3, 5th Alley, Miremad Avenue, Motehari Street, Zip Code: 1587958711, Tehran, Iran. E-mail: nedaboroushak@yahoo.com

\begin{abstract}
Head injuries are dangerous injuries that are common in combat sports. Nevertheless, the mechanisms of concussion in sport have are not precisely known. Thus, this study aimed to investigate the dynamic response of the head based on linear and rotational accelerations in boxing using computer simulation. The ADAMS software model was used to determine the linear and rotational acceleration of boxing's straight punch. The peak linear acceleration, average linear acceleration, peak rotational acceleration, and average rotational acceleration resulted from the straight punch to head were obtained: $75 \mathrm{~g}, 20 \mathrm{~g}, 4036 \mathrm{rad} / \mathrm{s}^{2}, 1140 \mathrm{rad} / \mathrm{s}^{2}$, respectively; the impact times were $30 \mathrm{~ms}$ and $3 \mathrm{~ms}$, respectively. The comparison of acceleration tolerance thresholds of head injury and obtained results of this study showed the rotational acceleration only leads to head injury. Furthermore, it is biomechanically improbable that the head would be moved only translationally or rotationally as a result of a straight punch. Therefore, both rotational and linear accelerations should be observed together for future studies.
\end{abstract}

Keywords: punch, linear acceleration, rotational acceleration, dynamic response

@MJSSMontenegro

HEAD'S DYNAMIC RESPONSE TO BOXING PUNCH

http://mjssm.me/?sekcija=article\&artid=210

Cite this article: Boroushak, N., Khoshnoodi, H., \& Rostami, M. (2021). Investigation of the Head's Dynamic Response to Boxing Punch Using Computer Simulation. Montenegrin Journal of Sports Science and Medicine, 10 (1), 31-35. doi: 10.26773/mjssm.210305

\section{Introduction}

Brain damage due to a blow to the head is a serious and significant social and public health problem and has attracted the attention of many researchers in recent years (Chen, 2012). Such injuries may occur in some cases without any apparent brain damage, but they may lead to severe cerebral injury, unconsciousness and death (Wu et al., 2019). The athletes in combat sports, such as boxing, karate, and taekwondo, are exposed to significant forces to the head induced by repeated and targeted blows. Superficial brain injuries due to blows are very common in these sports (Schmitt, Niederer, Cronin,
Muser, \& Walz, 2014; Walilko, Viano, \& Bir, 2005). Most brain injuries and traumas occur due to direct and repeated blows from near distances to the head in martial arts competitions, although these repeated blows may seemingly have no primary symptoms (Hoshizaki, Post, Oeur, \& Brien, 2014; Viano et al., 2005). The straight punch to the head is one cause of injuries in boxing (Viano et al., 2005).

Most of the previous studies have investigated the blow to the head and the biomechanics of injuries, focusing on concussions due to traffic accidents or incidents in sports, such as football, but few studies have dealt with concussions due to di- 
rect punches to head and repeated blows for obtaining points in martial arts competitions (Beaudouin, Aus der Fünten, Tröß, Reinsberger, \& Meyer, 2019, 2020; Putukian et al., 2019; Rowson, Brolinson, Goforth, Dietter, \& Duma, 2009). Viano et al. studied the punch force of eleven Olympic boxers with a 3D model; they investigated not only the direct punch but also the hook and uppercut blows and came to the conclusion that punches cause fewer injuries because of the short time of accelerating; therefore, they do not meet the criterion for brain damage (Viano et al., 2005). Zong et al. presented a 3D finite element model of the human head to assess the possibility of head injury due to the applied blows; the high possibility of spinal cord injury as a result of the wave propagation of stress inside the head was suggested (Zong, Lee, \& Lu, 2006). While these studies have provided insight into the mechanisms of head injury, the exact mechanism of head injury has not yet been determined.

Primary investigations show that the key factors were changes in intracranial pressure and skull deformation by using impact forces and cadaver heads. Denny-Brown Russell proposed that head rotation and movement can be noticeable factors (Denny-Brown \& Russell, 1941). It has nevertheless not been fully elucidated how outside forces are transmitted internally, nor is it precisely understood what the underlying injury of it is. At present, there are two main mechanisms of head injury: linear and rotational accelerations (Kis et al., 2013; Rowson et al., 2009). Linear acceleration produces focal brain damage, while rotational acceleration generates focal and diffuse brain injuries (Schmitt et al., 2019).

The applied impact forces to the head can lead to various reactions and injuries to the head and neck, depending on the intensity, complexity, location, and direction of the forces. These injuries can target a wide range of layers (e.g., skin, bone, brain layers, brain vessels) and structures (e.g., the eyes, nose, ears, and mouth). Various methods are used to study these effects on the human body (Motherway, Doorly, Curtis, \& Gilchrist, 2009; Zong et al., 2006). Among these, computer simulations have made significant contributions to medical, engineering, and sports science.

Despite using headgear in combat sports, concerns over repetitive blows to the head, which may cause considerable cognitive impairments, have increased. Investigating and understanding the mechanism of traumatic injuries to the human head and brain damage is one of the most critical issues of biomechanical studies of head injuries. The effects of forces applied to the head, which appear as accelerations in the head, are important factors in measuring injury. These effects can be measured using simulation methods, but they have been largely ignored in previous studies. They have focused on the wave propagation of stress inside the head. Therefore, this field is a novel topic that is examined in the present study. It can reduce medical costs and prevent head injuries. Therefore, due to the importance of linear acceleration and rotational acceleration parameters in investigating the biomechanics of head injury and the ambiguity of its effect on martial arts, such as boxing, as well as the safety of simulation methods compared to laboratory methods, the current study aims to examine the dynamic response of the head to the boxing punch using computer simulation.

\section{Methods}

In this study, at first, an appropriate model of the punch, head, and neck provided by simulation in Mechanical Dynamics Incorporation (MSC) Automated Dynamic Analysis of Mechanical Systems (ADAMS) software (MSC Software Corporation, 2013 version). Head properties such as stiffness, material, the properties of a hit (i.e., modulus of elasticity of skin and skull), damping factor in the impact and other parameters are variables related to contact.

Modelling of the neck with the accurate representations of the features of the human neck and body was an essential part of the simulation. Due to the connection of the head to the neck and body after the force is applied, angular acceleration is created on the head, and the behaviour of the neck is exemplified. Hence, based on the realistic response of the human body to the impact, an appropriate model of the neck with the required and optimum length and stiffness was obtained. In this model, the characteristics and behaviour of the neck and body are simulated by a clamped-free beam. Neck properties included equivalent flexibility, damping coefficient and equiv-

Table 1. Physical and Mechanical Parameters of Simulated Organs

\begin{tabular}{|c|c|c|}
\hline Body Part & Parameter & Amount of Parameter \\
\hline \multirow{5}{*}{ Neck and Body } & Equivalent Length & $30 \mathrm{~cm}$ \\
\hline & Equivalent Material & Steel \\
\hline & Equivalent Diameter & $1 \mathrm{~cm}$ \\
\hline & Diameter & $25 \mathrm{~cm}$ \\
\hline & Stiffness & $200 \mathrm{~N} / \mathrm{m}$ \\
\hline \multirow[t]{5}{*}{ Head } & Damping Coefficient & 12 \\
\hline & Penetration Depth in Impact & $4 \mathrm{~cm}$ \\
\hline & Mass & $5 \mathrm{~kg}$ \\
\hline & Hand Velocity & $6.7 \mathrm{~m} / \mathrm{s}$ \\
\hline & Effective Mass & $4.4 \mathrm{~kg}$ \\
\hline \multirow[t]{5}{*}{ Punch } & Shoulder Backward for Impact & $5 \mathrm{~cm}$ \\
\hline & The Stiffness Coefficient of Equivalent Linear Spring in Shoulder Joint & $30 \mathrm{~N} / \mathrm{m}$ \\
\hline & The Equivalent Damping Coefficient in Shoulder Joint & $4 \mathrm{~N} . \mathrm{S} / \mathrm{m}$ \\
\hline & Pre-Loading Force & $1500 \mathrm{~N}$ \\
\hline & Force of Punch & $4236 \mathrm{~N}$ \\
\hline
\end{tabular}


alent length. The mechanical properties of the head and neck were adapted from a previous study (Boroushak, Eslami, Kazemi, Daneshmandy, \& Johnson, 2018).

Furthermore, the features of punch for modelling were adopted from the study of Walilko et al. (Walilko et al., 2005). After determining the mechanical properties of the system components (Table 1), the motion constraints of the set were created. The hand moves along the shoulder using a linear spring with a stiffness of $\mathrm{k}$. This design was used based on the experimental methods in previous studies (Oeur, 2012). After determining the desired model, a direct punch was applied to the lateral of the head in simulation conditions, because most of the blows to the head in martial arts are applied in the lateral direction of the head. The resulting dynamic response (linear and rotational acceleration) was obtained. Finally, the results were compared with head injury thresholds.

\section{Results}

Figure 1 illustrates that straight punch to head in boxing with an impact force of $4236 \mathrm{~N}$ produces a mean and peak of linear acceleration of $20 \mathrm{~g}$ and $75 \mathrm{~g}$, respectively. Figure 2 shows that the average and peak of rotational accelerations of the head caused by a straight punch was $1140 \mathrm{rad} / \mathrm{s}^{2}$ and $4036 \mathrm{rad} / \mathrm{s}^{2}$, respectively. The impact duration was specified as $30 \mathrm{~ms}$ in the acceleration-time curve. By comparing the linear acceleration curves with the threshold tolerance curve of the head, it can be stated that the created acceleration will be located below the linear acceleration threshold (Figure 3). Also, a comparison of the rotational acceleration-time curve of the current study to the rotational acceleration threshold values of the head (Ommaya, Goldsmith, \& Thibault, 2002) concluded that the values obtained were within the head injury threshold.

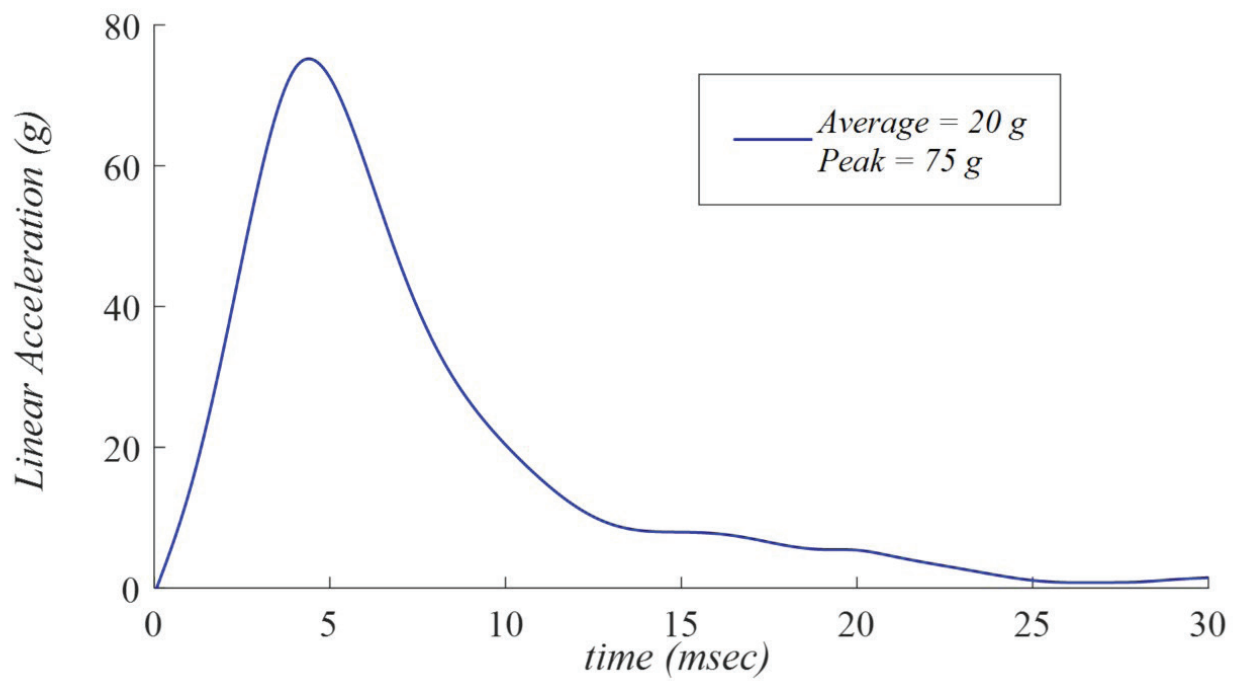

FIGURE 1. Head Linear Acceleration vs Time. $G=9.8 \mathrm{~m} / \mathrm{s}^{2}$

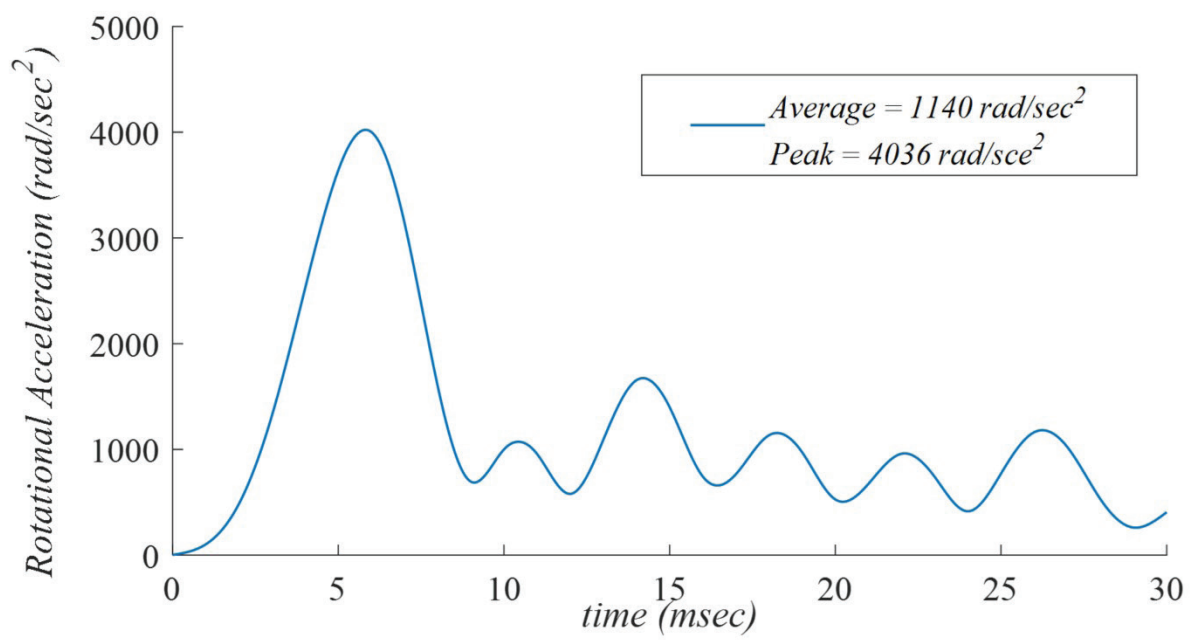

FIGURE 2. Head Rotational Acceleration vs Time

\section{Discussion}

The present study simulated the straight punch by using MSC ADAMS software and evaluated the linear and rotational acceleration responses on the head.

The Wayne State University Cerebral Concussion Tolerance Curve (WSTC) was established as a result of extensive cadaver assessments which focus on head acceleration; it shows a relationship between the duration and the mean of anterior-posterior translational acceleration magnitude that drives from similar head damage severity in head contact impacts. When this combination lies above the curve, it exceeds human tolerance, meaning that it makes extreme and 


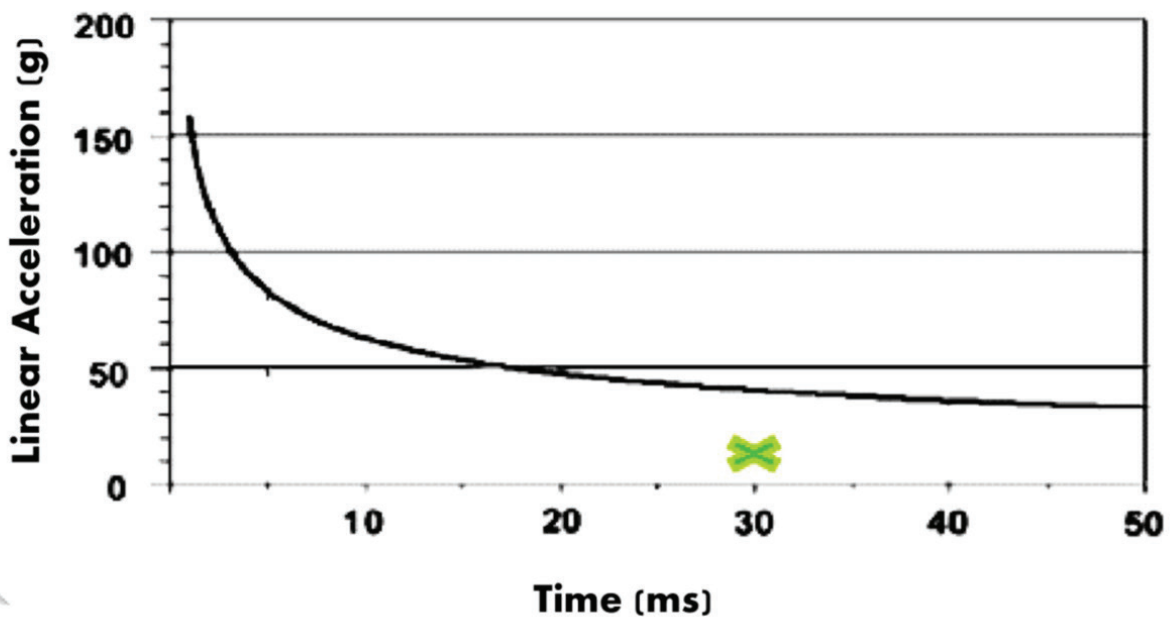

FIGURE 3. Comparison of Obtained Linear Acceleration with The Threshold Tolerance Curve of the head injury

irreversible brain injury. While the combinations below the curve do not exceed human tolerance, they may result in reversible injuries (Ommaya et al., 2002). In the current study, the average and peak of linear acceleration caused by a punch were obtained $20 \mathrm{~g}$ and $75 \mathrm{~g}$, respectively. Also, their durations were $30 \mathrm{~ms}$ and $3 \mathrm{~ms}$, respectively (Figure 2). According to the WSTC, these amounts are located below the curve; therefore, they cannot lead to severe damage.

Atha et al. conducted some experiments for a heavyweight boxer using a ballistic pendulum (Atha, Yeadon, Sandover, \& Parsons, 1985). They obtained a peak of linear acceleration as $53 \mathrm{~g}$. Smith et al. also gained a linear acceleration of $43.6 \mathrm{~g}$ for punches from boxers (Smith, Dyson, Hale, \& Janaway, 2000). Fife et al. reported that the peak of linear acceleration resulting from a punch to the head is $71.23 \mathrm{~g}$ (Fife, O'Sullivan, \& Pieter, 2013). Walilko et al. assumed the peak of linear acceleration for Olympic boxers' punch, 58g (Walilko et al., 2005). All these researchers used the threshold of head injury for linear acceleration proposed by Ommaya et al. (2002). The risk of traumatic brain injury from these straight punches inducing translational acceleration is low (less than 2\%). Therefore, it can be stated that the results obtained from the present study are in accordance with these previous studies.

It should be noted that if the head is exposed to such accelerations repeatedly, the tolerance and resistance may decrease against the impacts due to the presence of frequent tensions, which leads to the increased duration of acceleration or rising of acceleration amount, which will likely be accompanied by the displacement of the intersection location of the acceleration and time to above the WSTC. In other words, irreversible injuries occur. Since boxers are exposed to repeated blows to the head, this can lead to brain injury in the long term.

The current study also showed the average and peak of rotational accelerations of the head as $1140 \mathrm{rad} / \mathrm{s}^{2}$ and $4036 \mathrm{rad} /$ $\mathrm{s}^{2}$, respectively. According to Löwenhielm's study, head acceleration of $4500 \mathrm{rad} / \mathrm{s}^{2}$ causes the rupture of the bridging veins in the brain (Löwenhielm, 1975). An angular acceleration of $1800 \mathrm{rad} / \mathrm{s}^{2}$ was also proposed as the tolerance level for a $50 \%$ probability of concussion by Ommaya et al. (2002). Therefore, in our study, the obtained rotational acceleration put boxer athletes at risk for concussion.

However, the $4036 \mathrm{rad} / \mathrm{s}^{2}$ rotational acceleration is less than the injury threshold of Löwenhielm (1975); nevertheless, it may be accompanied by serious damage of the veins in the brain in repetitive blows to the head. In some other studies, different results were reported, which can be for various methods of testing or some properties and conditions of punches to the head such as the studies of Rowson et al. (2012) and Walilko et al. (2005). Rowson et al. determined that rotational acceleration created within the head is 1753 $\mathrm{rad} / \mathrm{s}^{2}$ via a simulation of punching in boxing. Walilko et al. reported that rotational acceleration caused by the punch of a $109 \mathrm{~kg}$ person to head, is $6343 \mathrm{rad} / \mathrm{s}^{2}$ (Rowson et al., 2012; Walilko et al., 2005).

Generally, according to the results obtained in the current study, it can be stated that in the boxing head injuries, rotational acceleration is suspected of playing a significant role. Therefore, it should receive considerable attention. Probably, the translational component of acceleration in punching can be more easily resisted by neck muscles; therefore, greater muscle strength may increase its resistance against impact force and linear acceleration (Schmitt et al., 2019). The structure and physical properties of brain tissue also are more resilient to compressive and tensile forces than rotational and shearing forces. As such, the translational acceleration injury threshold is higher than the rotational acceleration thresholds. So, the threshold of head injury tolerance for rotational acceleration is much lower due to the resistance of brain tissue layers against the shearing force that leads to rotation and the creation of shearing in brain tissue. Hence, rotational acceleration is associated with higher injury risk (Campbell, Gallagher, McLeod, O’Neill, \& McMillan, 2019; Schmitt et al., 2019).

The model simulated in this study is based on previous studies and is related to the general state of the biomechanical behaviour of the athlete's head. However, it should be considered that, in reality, everyone has different biomechanical behaviour and responses, which is not possible to simulate. Also, it should be noted that there is no possibility of biomechanically isolating the linear acceleration from the rotational acceleration in sport activities. Therefore, the consideration of both linear and rotational acceleration parameters for head injury thresholds is advised in order to examine more appropriate dynamic response of the head for future studies. 
Furthermore, to decrease the risk of brain injuries in boxing athletes, we recommend proper defensive techniques be practised and employed. To reduce the risk of concussion from punching, it is also suggested that, several measures be applied by the World Boxing Federation, including rules changes and proper headgears design.

\section{Acknowledgement}

The present study was adapted from a post-doctoral project supported by The Iran National Science Foundation, Number 97013316.

\section{References}

Atha, J., Yeadon, M., Sandover, J., \& Parsons, K. (1985). The damaging punch. Br Med J (Clin Res Ed), 291(6511), 17561757. doi: $10.1136 / \mathrm{bmj} .291 .6511 .1756$

Beaudouin, F., Aus der Fünten, K., Tröß, T., Reinsberger, C., \& Meyer, T. (2019). Head injuries in professional male football (soccer) over 13 years: 29\% lower incidence rates after a rule change (red card). British journal of sports medicine, 53(15), 948-952. doi: 10.1136/bjsports-2016-097217

Beaudouin, F., Aus der Fünten, K., Tröß, T., Reinsberger, C., \& Meyer, T. (2020). Match Situations Leading to Head Injuries in Professional Male Football (Soccer) - A Video-Based Analysis Over 12 Years. Clinical Journal of Sport Medicine, 30, S47-S52. doi: 10.1097/jsm.0000000000000572

Boroushak, N., Eslami, M., Kazemi, M., Daneshmandy, H., \& Johnson, J. A. (2018). The dynamic response of the taekwondo roundhouse kick to head using computer simulation. Ido Movement for Culture. Journal of Martial Arts Anthropology, 18(2), 54-60. doi: 10.14589/ido.18.2.8.

Campbell, I. N., Gallagher, M., McLeod, H. J., O’Neill, B., \& McMillan, T. M. (2019). Brief compassion focused imagery for treatment of severe head injury. Neuropsychological rehabilitation, 29(6), 917-927. doi: 10.1080/09602011.2017.1342663

Chen, Y. (2012). Biomechanical analysis of traumatic brain injury by MRI-based finite element modeling. University of Illinois at Urbana-Champaign.

Denny-Brown, D., \& Russell, W. R. (1941). Experimental cerebral concussion. Brain, 64(2-3), 93-164. doi: 10.1093/ brain/64.2-3.93

Fife, G., O'Sullivan, D., \& Pieter, W. (2013). Biomechanics of head injury in Olympic taekwondo and boxing. Biology of sport, 30(4), 263-238. doi: 10.5604/20831862.1077551

Hoshizaki, T. B., Post, A., Oeur, R. A., \& Brien, S. E. (2014). Current and future concepts in helmet and sports injury prevention. Neurosurgery, 75(suppl_4), S136-S148. doi 10.1227/NEU.0000000000000496

Kis, M., Saunders, F. W., Kis Sr, M., Irrcher, I., Tator, C. H., Bishop, P. J., \& Martin, W. (2013). A method of evaluating helmet rotational acceleration protection using the Kingston Impact Simulator (KIS Unit). Clinical Journal of Sport Medicine, 23(6), 470-477. doi: 10.1097/ JSM.0b013e318295a80f

Löwenhielm, P. (1975). Mathematical simulation of gliding contusions. Journal of Biomechanics, 8(6), 351-356. doi 10.1016/0021-9290(75)90069-X
Motherway, J., Doorly, M. C., Curtis, M., \& Gilchrist, M. D. (2009). Head impact biomechanics simulations: A forensic tool for reconstructing head injury? Legal Medicine, 11, S220-S222. doi: doi.org/10.1016/j.legalmed.2009.01.072

Oeur, A. (2012). An analysis of head impact angle on the dynamic response of a Hybrid III headform and brain tissue deformation: University of Ottawa (Canada).

Ommaya, A., Goldsmith, W., \& Thibault, L. (2002). Biomechanics and neuropathology of adult and paediatric head injury. British journal of neurosurgery, 16(3), 220-242. doi: 10.1080/02688690220148824

Putukian, M., Echemendia, R. J., Chiampas, G., Dvorak, J., Mandelbaum, B., Lemak, L. J., \& Kirkendall, D. (2019). Head Injury in Soccer: From Science to the Field; summary of the head injury summit held in April 2017 in New York City, New York. British journal of sports medicine, 53(21), 1332-1332. doi: 10.1136/bjsports-2018-100232.

Rowson, S., Brolinson, G., Goforth, M., Dietter, D., \& Duma, S. (2009). Linear and angular head acceleration measurements in collegiate football. Journal of biomechanical engineering, 131(6). doi: 10.1115/1.3130454

Rowson, S., Duma, S. M., Beckwith, J. G., Chu, J. J., Greenwald, R. M., Crisco, J. J., Maerlender, A. C. (2012). Rotational head kinematics in football impacts: an injury risk function for concussion. Annals of biomedical engineering, 40(1), 1-13. doi: 10.1007/s10439-011-0392-4

Schmitt, K.-U., Niederer, P. F., Cronin, D. S., Morrison III, B., Muser, M. H., \& Walz, F. (2019). Head injuries Trauma Biomechanics (pp. 87-115): Springer.

Schmitt, K.-U., Niederer, P. F., Cronin, D. S., Muser, M. H., \& Walz, F. (2014). Verletzungen der Wirbelsäule TraumaBiomechanik (pp. 91-131): Springer.

Smith, M., Dyson, R., Hale, T., \& Janaway, L. (2000). Development of a boxing dynamometer and its punch force discrimination efficacy. Journal of sports sciences, 18(6), 445-450. doi: 10.1080/02640410050074377

Viano, D. C., Casson, I. R., Pellman, E. J., Bir, C. A., Zhang, L., Sherman, D. C., \& Boitano, M. A. (2005). Concussion in professional football: comparison with boxing head impacts-part 10. Neurosurgery, 57(6), 1154-1172. doi: 10.1227/01.NEU.0000187541.87937.D9

Walilko, T., Viano, D. C., \& Bir, C. A. (2005). Biomechanics of the head for Olympic boxer punches to the face. British journal of sports medicine, 39(10), 710-719. doi: 10.1136/ bjsm.2004.014126

Winter, D. A. (2009). Biomechanics and motor control of human movement: John Wiley \& Sons. doi: 10.1002/9780470549148

Wu, L., Chung, J. Y., Saith, S., Tozzi, L., Buckley, E. M., Sanders, B., . . . Lok, J. (2019). Repetitive head injury in adolescent mice: A role for vascular inflammation. Journal of Cerebral Blood Flow \& Metabolism, 39(11), 2196-2209. doi: 10.1177/0271678X18786633

Zong, Z., Lee, H., \& Lu, C. (2006). A three-dimensional human head finite element model and power flow in a human head subject to impact loading. Journal of Biomechanics, 39(2), 284-292. doi: 10.1016/j.jbiomech.2004.11.015 